Journal Port Science Research $v o l: 2$, No:2, 2019

$\overline{\mathrm{PAPER}} \cdot$ Full original article online Free

\title{
Representations of psychological security in the artistic expression of displaced students
}

*Noora Abdullah Ali $\quad \& \quad$ Shailer Abdullah Ali

Directorate of Baghdad Education Karkh III, Ministry of Education, Baghdad, Iraq Mahmoud_mahdi74@yahoo.com

$$
\begin{aligned}
& \text { تمثالات الامن النفسي في التعبير الفني للى الطالبات النازحات }
\end{aligned}
$$

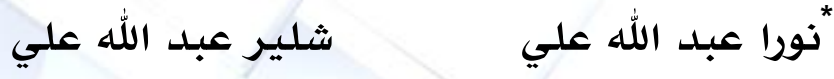

$$
\begin{aligned}
& \text { وزارة التربية، مديرية تربية بغداد الكرج الثالثة، بغداد، العراق }
\end{aligned}
$$

Mahmoud_mahdi74@yahoo.com

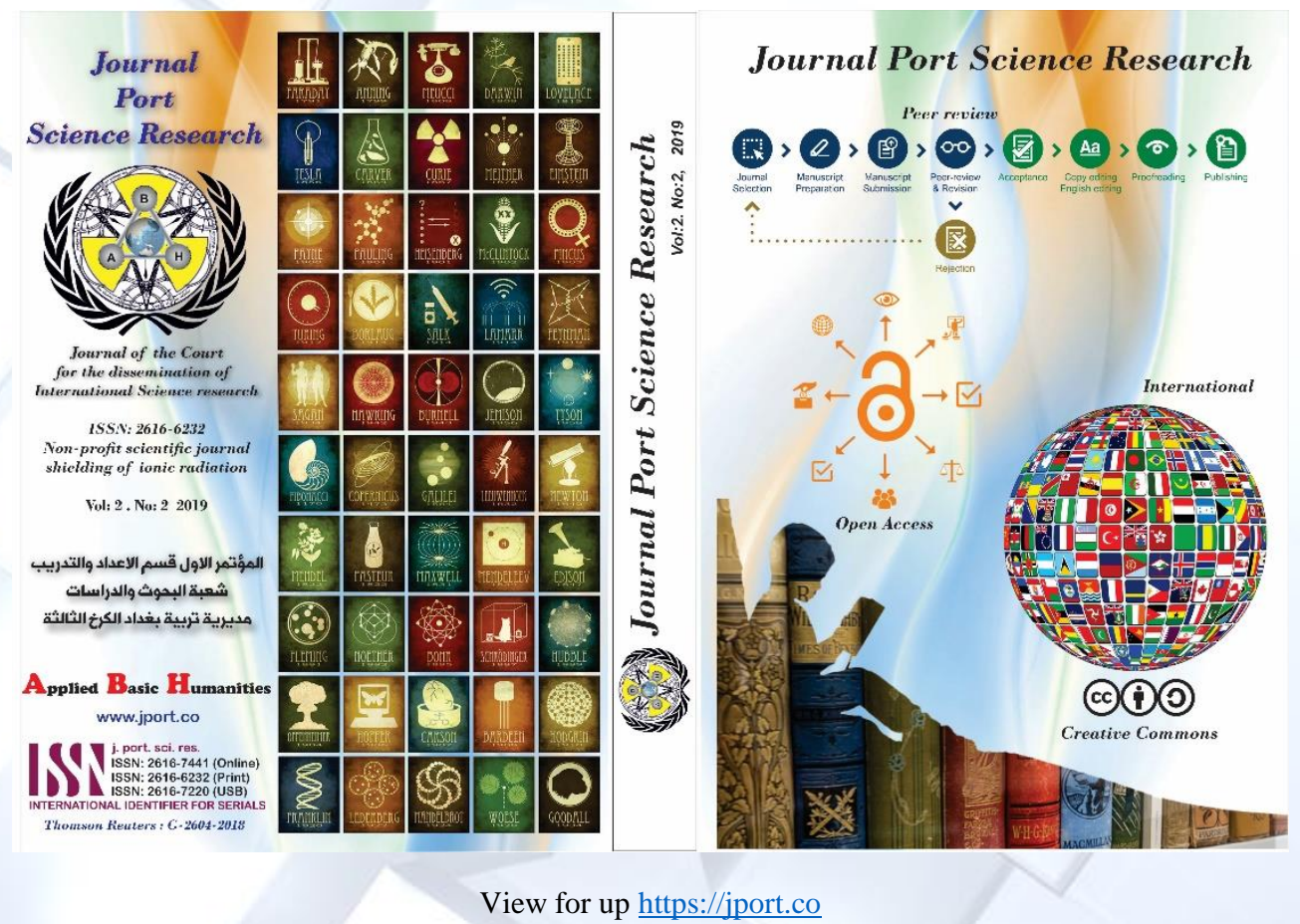

To cite this article: Published 2019 • (C) 2019 Bryant University United States of America Publishing Ltd. 
Ministry of Education Iraqi Directorate of Education Baghdad Karkh III

First Conference Department of Preparation and Training Division of Research and Studies

وزارة التربية العراقية مديرية تربية بغداد الكرخ الثالثة المؤتمر الاول قسم الاعداد والتلدريب شعبة البحوث واللدراسات

\title{
Representations of psychological security in the artistic expression of displaced students
}

\author{
*Noora Abdullah Ali \& Shailer Abdullah Ali \\ Directorate of Baghdad Education Karkh III, Ministry of Education, Baghdad, Iraq \\ Mahmoud_mahdi74@yahoo.com
}

\begin{abstract}
Identify level of The Future anxiety, in the fees of students displaced by measuring the level of anxiety, on a gauge Abraham Maslow. Analysis of the fees of the IDP students on the fee analysis form. The sample consisted of (32) students from the preparatory stage, the researchers used the psychological security measure consisting of (47) paragraph, and the tool to analyze the fees of students and the (7) Of the technical characteristics, have been achieved honesty and consistency, and reached the results, including. The low level of feeling of psychological security among the students was evident in their drawings because of the influence of the conditions experienced by the student during the period of terrorism. In the light of the results, recommendations and suggestions were reached.
\end{abstract}

Keywords: Psychological security, Technical expression.

\section{تمثلات الامن النفسي في التعبير الفني للى الطالبات النازحات}

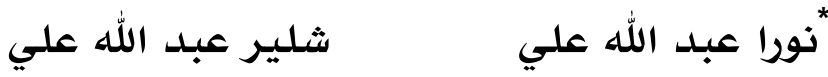 \\ وزارة التربية، مديرية تربية بغداد الكرخ الثالثة، بغداد، العراق \\ Mahmoud_mahdi74@yahoo.com
}

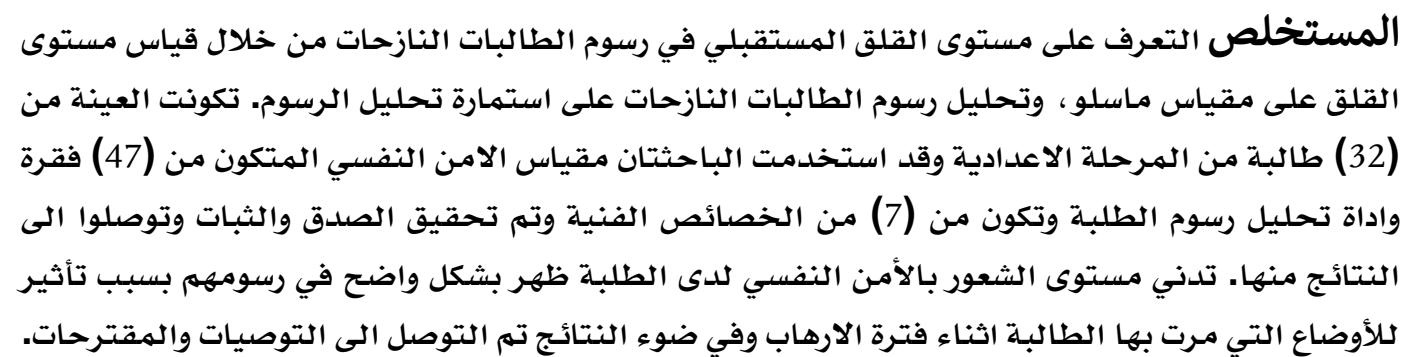

الكلمات اللدالة: الأمن النفسي، التعبير الفني.

Ali, N. Ali, S. (2019). Representations of psychological security in the artistic expression of displaced students. Journal Port Science Research, 2(2), 203-212. 


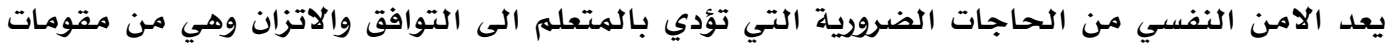

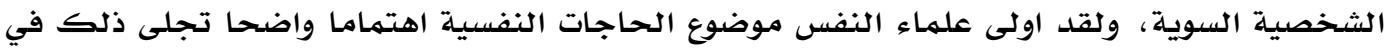

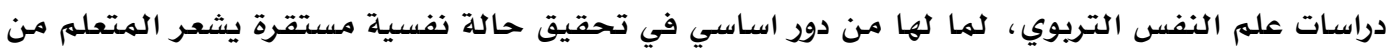

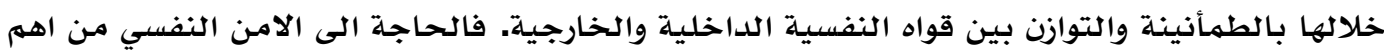

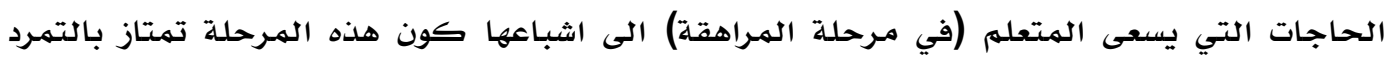

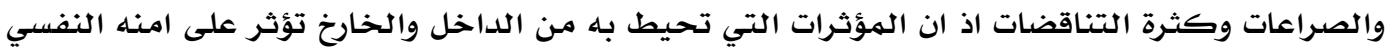

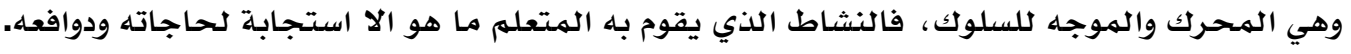

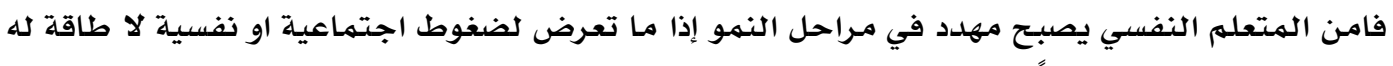

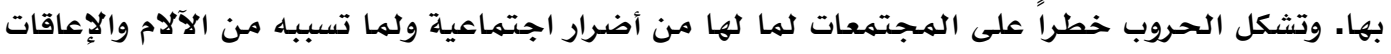

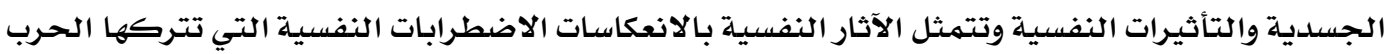

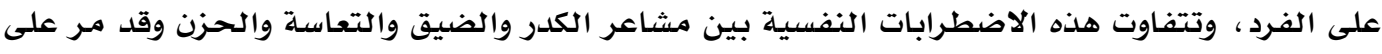

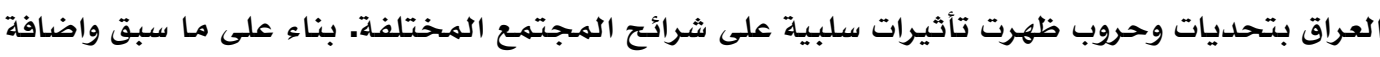

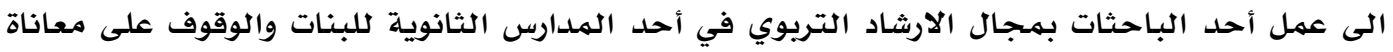

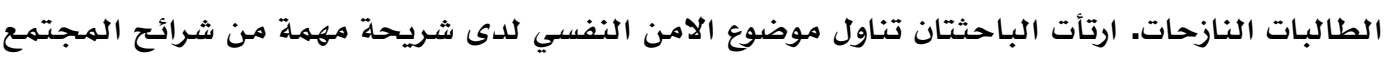

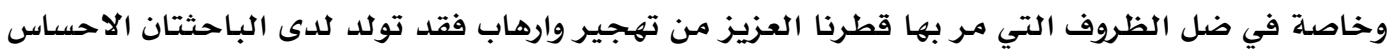

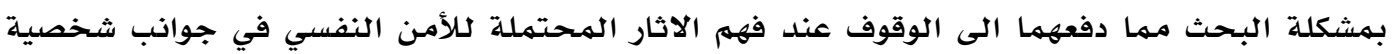

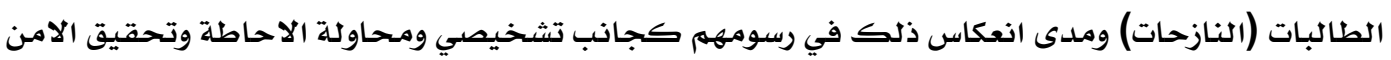

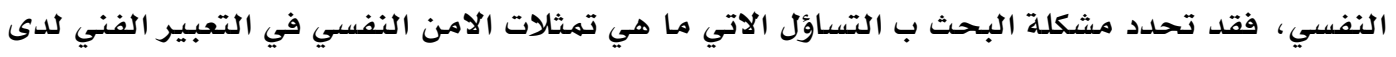

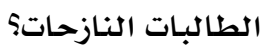

\section{اهمية البحث}

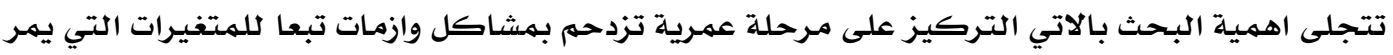

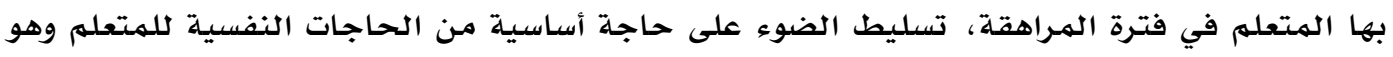

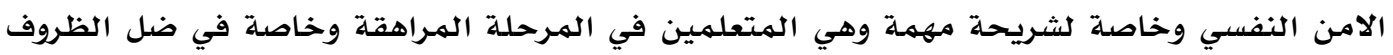

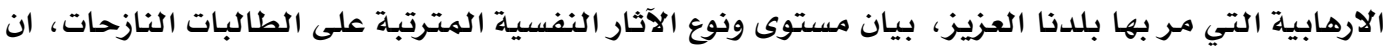

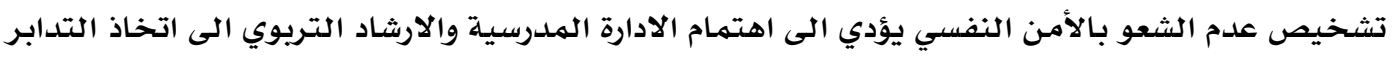
واعداد البرامج العلاجية لرفع مستوى المن بالامن النفي يودي النفى اهتي لدى الادارة المتعلمين.

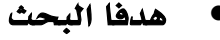

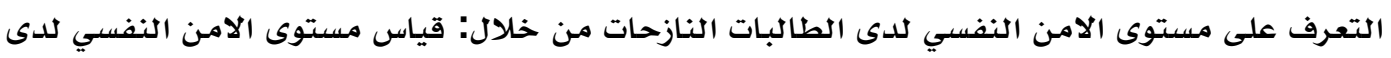

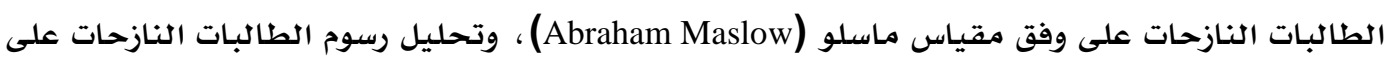
وفق استمارة تحليل الرسوم

الحمد الموضوعي يتحدد البحث الحالي بمستويات الامن النفسي للطالبات النازحات في المرحلة الإعدادية

$$
\text { من خلال التعبير الفني. }
$$


الحد المكاني المدارس التابعة للمديرية العامة لتربية بغداد - الكرج 3 (اعدادية رقية بنت الحسين

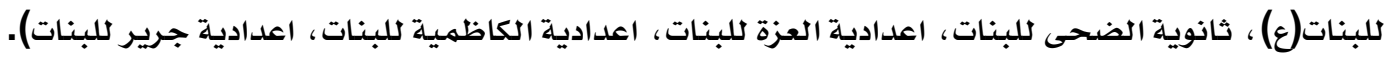
الحد الزماني كان العام الدراسي 2019-2018

•

تمثلات عرفها جميل (2002): بانها أدراك المضمـون المشخص كمـل فهـلـل ذهنــي والتمثل هو تصور الشي [1].

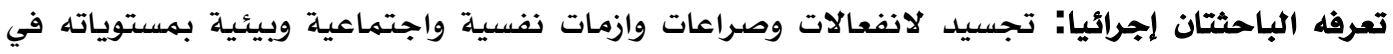
التعبير الفني التشكيلي لدى الطالبات النازحات في المرحلة الاعدادية.

الامن النفسي عرفـه (Abraham Maslow، (1994): الشعـور بالأمن والحماية والنظام والقانـــون

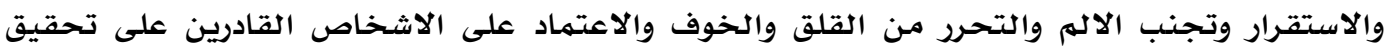
المتطلبات الحيوية [2].

تعرفه الباحثتان اجرائيا: هو انفعال ينتج عن عدم الاستقرار النفسي والاجتماعي والشعور بالخوف أيا كان

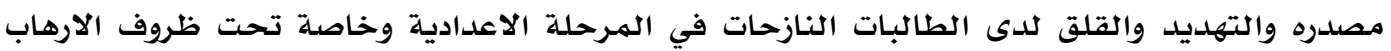
والتهجير. التعبير الفني مرفه مصطفى (2018): يعبر للمتعله عما يجول في نفسه بأسلوبه الخاص وترجمه

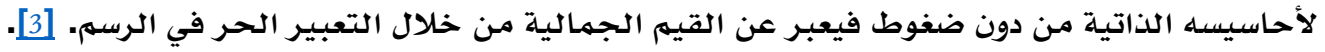

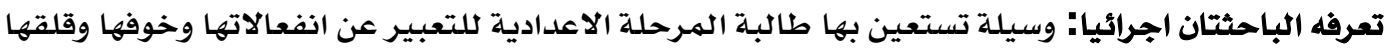

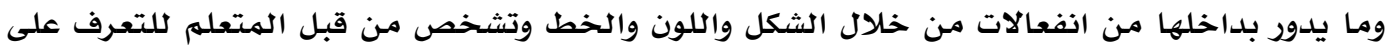
مستوى الامن النفسي لدى الطالبة النازحة.

\section{الإطار النظري ودراسات سابقة}

مفهوم الامن النفسي: يعد الأمن النفسي من الحاجات النفسية اللازمة للنمو النفسي والصحة النفسية

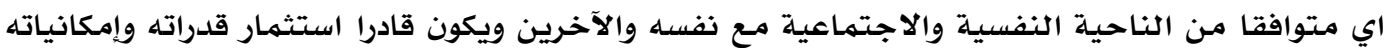
وعلى تحقيق ذاته، وقد اختلف مفهوم الأمن النفسي باختلاف الدارسين والباحثين واختلاف زاوية نظر التارئ

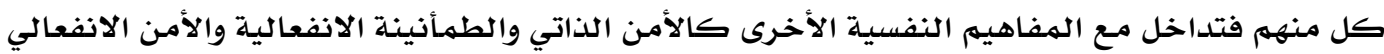

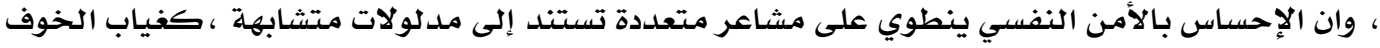

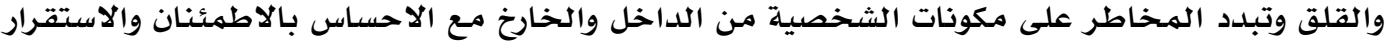

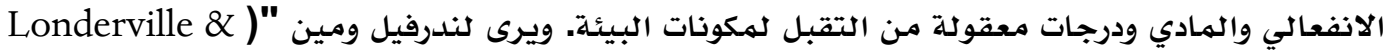

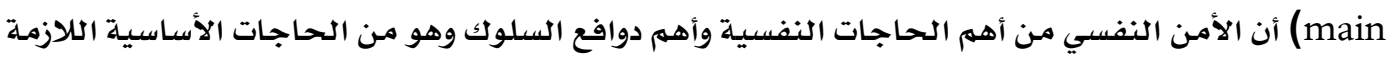

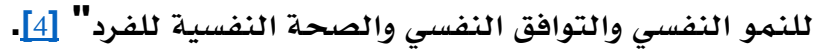

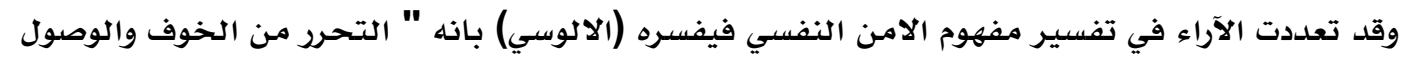

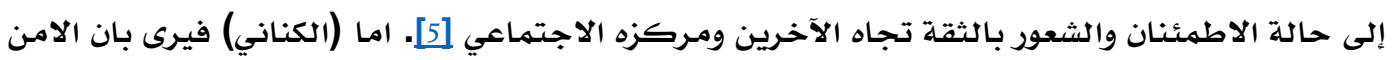

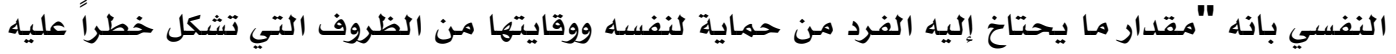

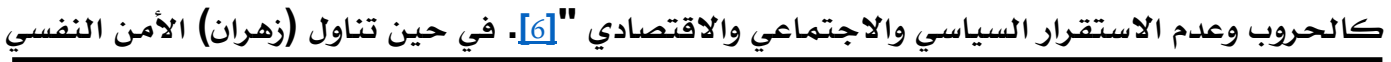
Ali, N. Ali, S. (2019). Representations of psychological security in the artistic expression of displaced students. Journal Port Science Research, 2(2), 203-212. 
بأنه "الطمأنينة النفسية أو الانفعالية لدى الفرد، وحالة يكون فيها إثباع الحاجات مضمونً وغير معرض للخطر ومحرك للفرد في تحقيق أمنه" [7] ويكمن الامن النفسي عند (عدس) ب "وجود علاقات متوازنة بين الفرد وذاته من ناحية وبينه وبين الأفراد الآخرين المحيطين به من ناحية أخرى، فإذا توافرت هذه

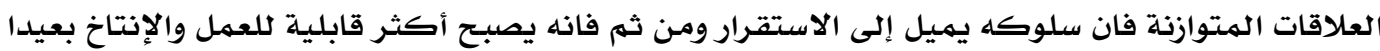

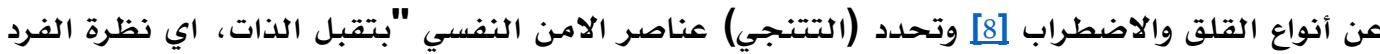

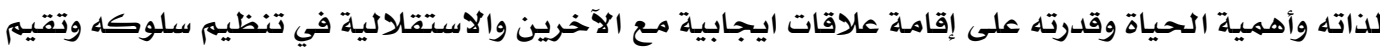
ذاته من خلال معايير محدده والسيطرة على البيئة الذاتية وإدراكه وإمكانياته السعي نحو تطويرها مـع

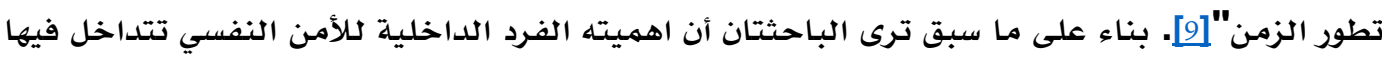

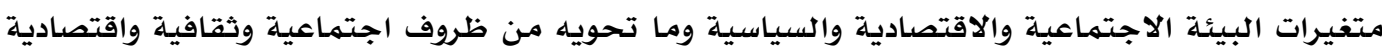
وسياسية في سياق خاص فهو يتأثر بالعديد مـ العوامل سلبا وإيجابا ويتداخل مـع الحاجـات الإنسانية

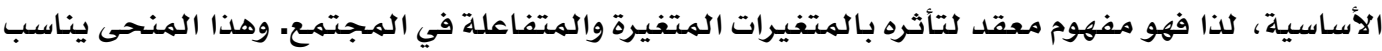
تصور الباحثتان لتناول الأمن النفسي في البيئة العراقية لما تعرضت لله البلد من عدم استقرار سياسي وعسكري وطالت جميع الفئات العمرية وخاصـة مرحلة المراهقة.

مفهوم التعبير الفني يعد التعبير الفني بالغ الاهمية في حياة البشريـة منذ القدم فهو وسيله للتعبير عن جوانب حياتهم وأحاسيسهم وأفعالهم قبل ان يصل الى معرفة الكتابة الكهوف كوسيلة الكيلة للتواصل مـع الاخرين

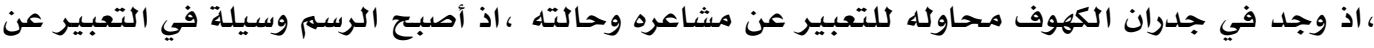

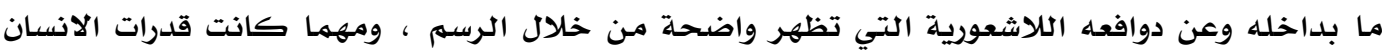
متتواضعة وخبراته السـابقة قليلة فانه قادر على التعبير عن اللاشعور من خلال الفن وطرقه ووسائله المختلفة إذ ليس هناك حدود زمنية أو القدرة العقلية حيث تمتلك هذه الرسوم الصفية السيكولوجية

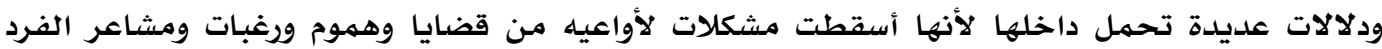

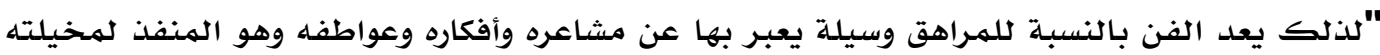
الحية، واحد أشكال النشاط العقلي الذي يضيء حجرات المخيلة وينشط الفكر." [10] فيظهر نشاط الفن والتربية الفنية بالنسبـة للمراهق كمحاولة جيدة لتفريـ تلك الشحنـات السلبيـة داخله فيتخلص بها يشعر بـه من توتراث ويقول فكتورنفيلد (Lowonfold) بهذا الصدد قد يكون الفن هو التوازن الضروري لعقلية المراهق وعواطفه وانفعالاته وأخيلته وقد يصبح الصديق الذي يتجه أليه حتى بطريقة لا شعورية

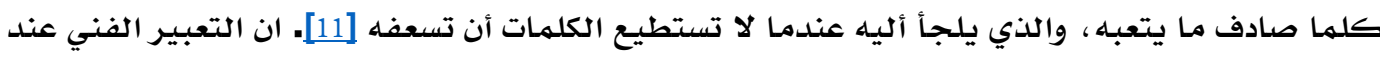
الافراد قد يكون الدافع اليه هو التعبير عن احباط في الرغبات لهم يسمـح لها بالإثباع والتحقيق، فلهم تجد غير التعبير الفني مخرجا لها وهنا يكون التعبير الفني وسيلة لإسقاط مـخاوف الفرد وافكاره على الاثكال

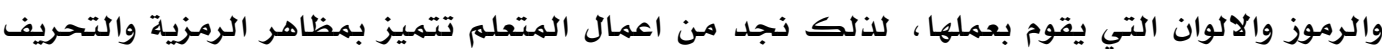
وجميعها وسـائل تعبير تعكس حياة المتعله وتهدف الى اعادة ترتيب عالمـه الواقعي الذي يعيشه الى عالم خاص من وضعه يخضعه لرغباته وميوله الخاصدة.

\section{2. المنهجية والاجراءات}

اتبعت الباحثتان في البحث الحالي المنهج (الوصفي - التحليلي) لتحقيق أهداف بحثها. مجتمع البحث

يتألف مـجتمح البحث من الطالبات النازحات من مناطق مـتلفة من العراق ، نتيجة ما تعرضت لها

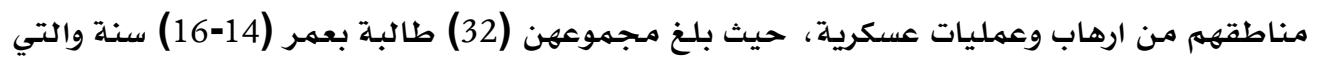
علي، نورا عبد الله. علي، شلير عبد الله. (2019). تمثلات الامن النفسي في التعبير الفني لدى الطالبات النازحات. 212-203 ، Journal Port Science Research 
يرادفها مرحلة المراهقة على تصنيف لوينفيلد 1952، فتوزعن على خمس مدارس تابعة الى المديرية العامـة لتربية بغداد (الكرج /3).

العينة الاستطلاعية: اختارت الباحثة طالبات مدرسة (اعدادية التضحية للبنات) والبالغ عددهن (6) كعينة

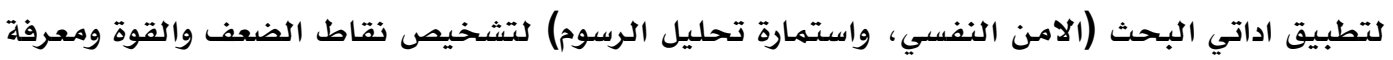

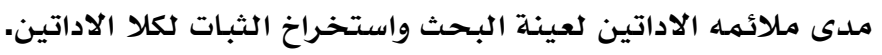

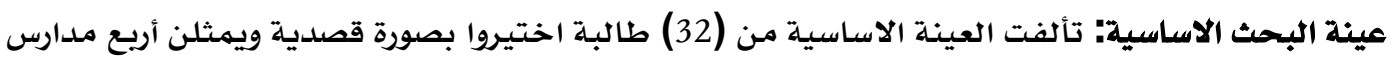
في الصف الرابع الاعدادي والتي يرادفها مرحلة المراهقة على تصنيف لوينفيلد 1952.

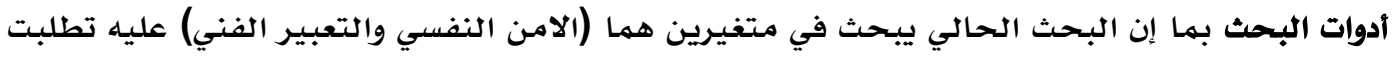

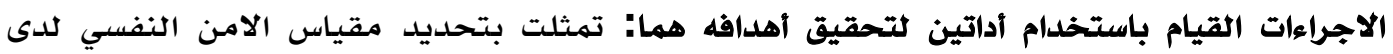

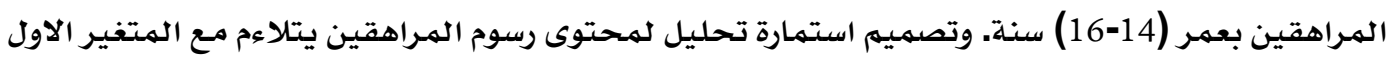

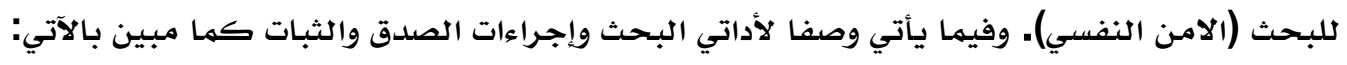

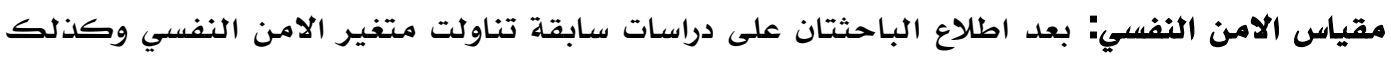

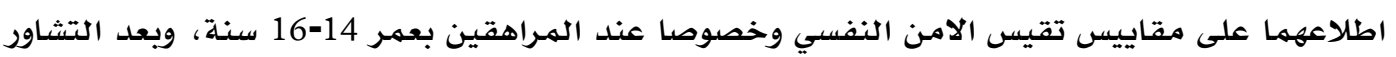
مع اصحاب الاختصاص (علم النفس، والقياس والتقويم) وقع الاختيار على مقياس (ماسلو) لأنه الأفضل

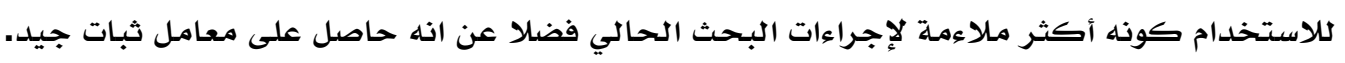

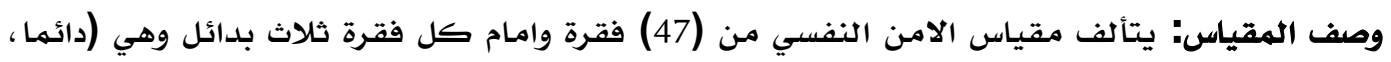

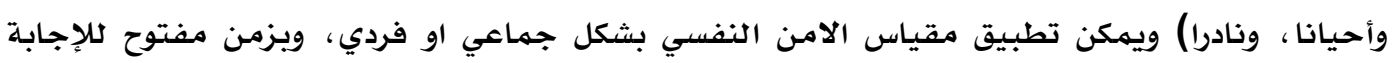

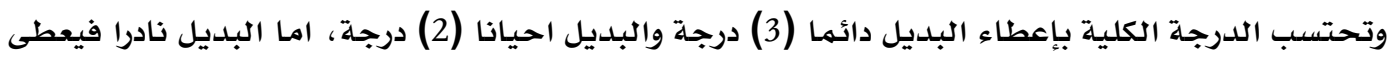
(1) درجة، وتجمع الدرجات للحصول على مستويات الامن النفسي.

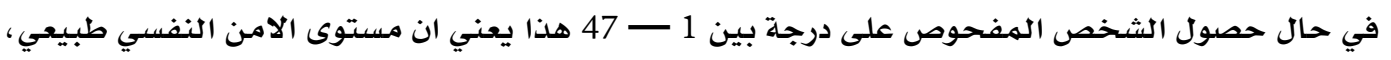

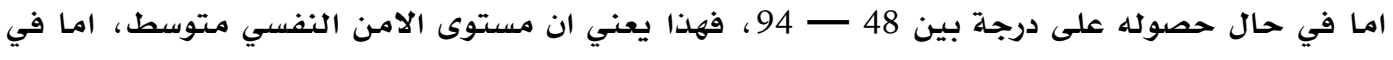

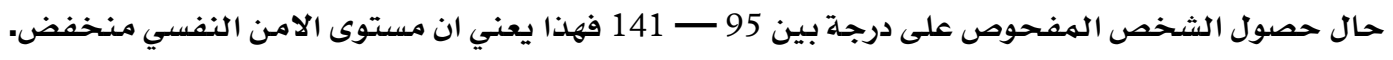

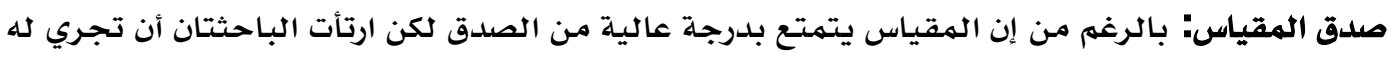

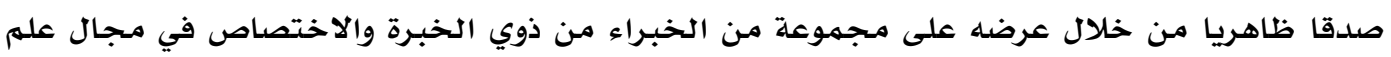

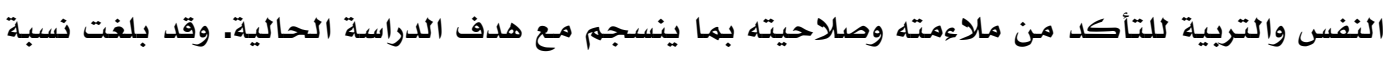

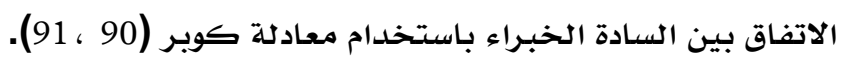

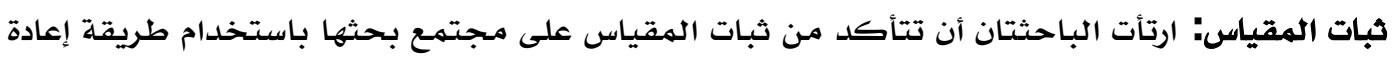

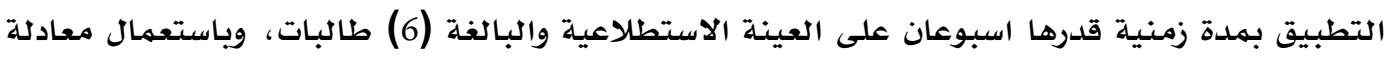

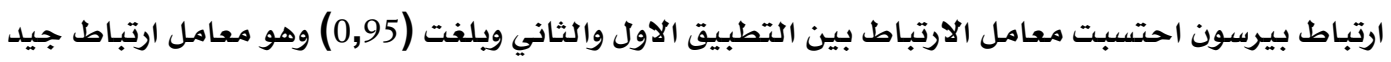
لقياس مستوى الامن النفسي لدى الطالبات النات النازحات.

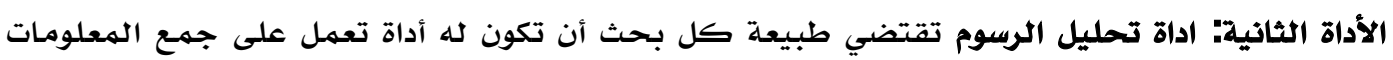

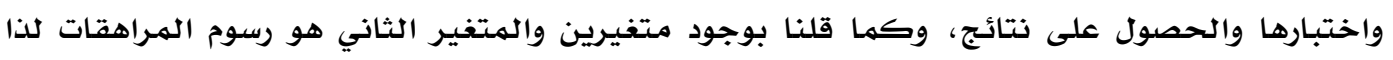

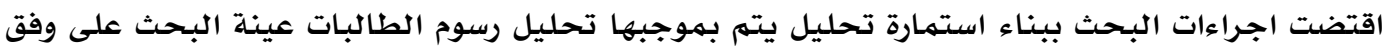

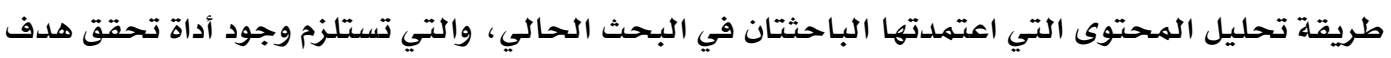
البحث وتلائم المادة المحللة. الئ.

Ali, N. Ali, S. (2019). Representations of psychological security in the artistic expression of displaced students. Journal Port Science Research, 2(2), 203-212. 
وصف الاداة: تتكون أداة تحليل الرسوم من سبع مجالات رئيسة وتتفرع منها (16) فقرة فرعية للرسهم، اما التصحيح فيعطى تكرار واحد لكل خاصية من الخواص الثلاثة للفقرة الواحدة في حالة ظهورها. صدق استمارة التحليل: بعد تحديد المجالات الرئيسية والفقرات الفرعية لأداة التحليل، عرضتئها

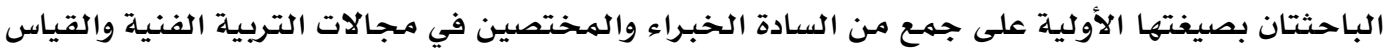

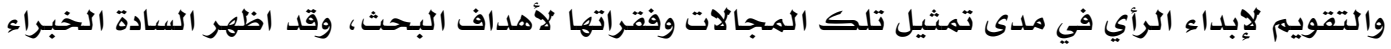

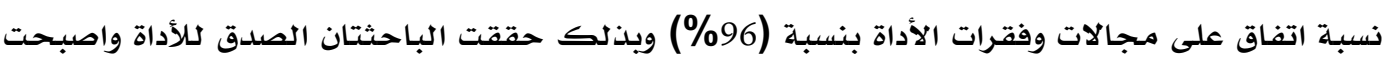
جاهزة لتطبيقها على العينة الاستطلاعية.

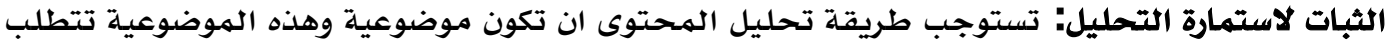

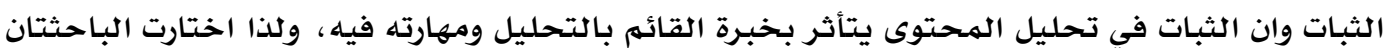

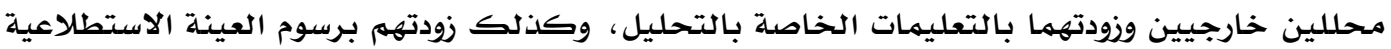

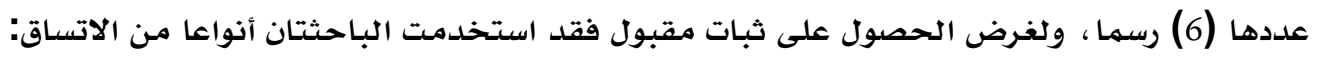

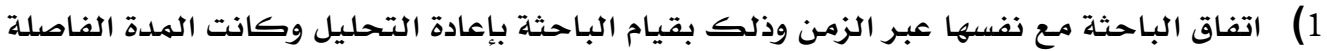

$$
\text { بين التحليلين (14) يوما. }
$$

2) الاتفاق بين المحللين الخارجيين إذ قاما بتحليل العينة نفسها بشكل مستقل.

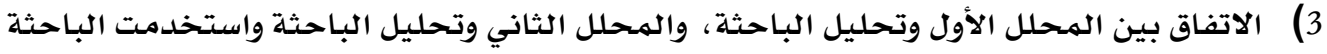

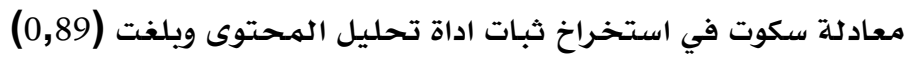

الدراسة الأساسية (التطبيق): بعد التحقق من صدق وثبات أداتي البحث قامت الباحثتان بدراستها الأساسية

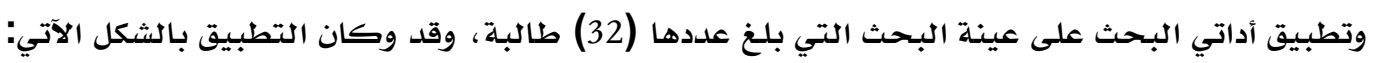

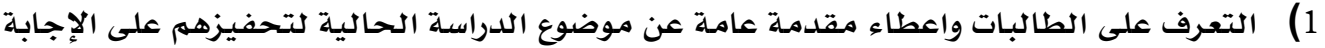

$$
\text { على أسئلة الاختبار. }
$$

2) ترتيب جلوس الطالبات بشكل يجعل كل واحد منهم لا يرى إجابات غيره ثم توزيع استمارات

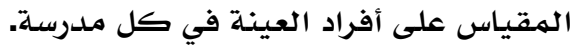

3) الوضيح كيفية الإجابة عن فقرات المقياس والإجابة عن استفسارات الطالبات.

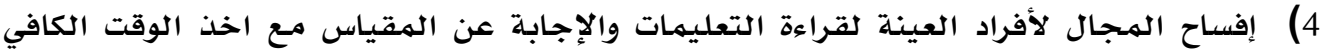

$$
\text { للتأشير. }
$$

5) جمع الاستمارات بعد انتهاء الطالبات من الإجابة.

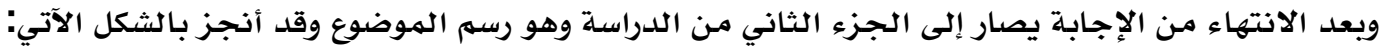

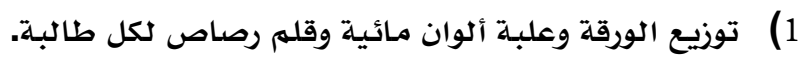$$
\text { 2) كتابة اسم الموضوع على السبورة موضوع حر. }
$$$$
\text { 3) ضبط الوقت المخصص للرسم وهو } 45 \text { دقيقة. }
$$

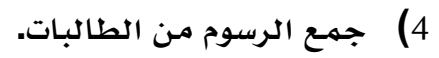

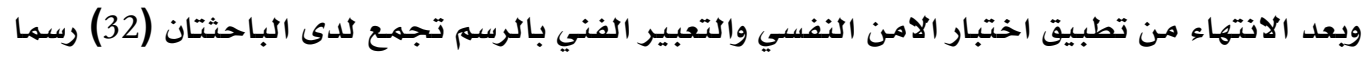

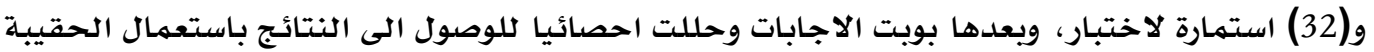

$$
\text { الاحصائية وكالاتي: }
$$

1) معادلة كوبر Cooper وقد استخدمت في حساب الصدق لأداتي البحث.

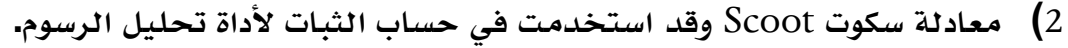

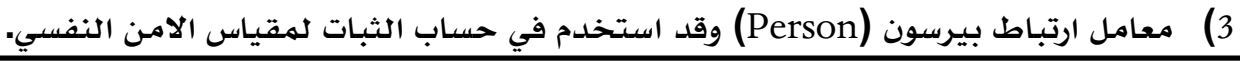

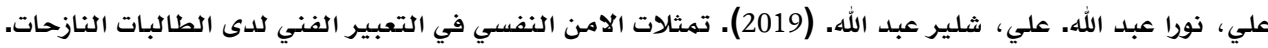


4) التكرارات استخدمت في حساب النسب المئوية لخصائص الرسوم لعينة البحث، ولتحديد

\section{3. تحليل وعرض النتائج}

يتضمن هذا الفصل عرضا للنتائج التي توصل اليها البحث وتفسيرها في ضوء اهدافها وعلى النحو الاتي:

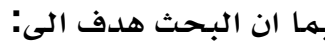

تعرف مستوى الامن النفسي في التعبير الفني لدى الطالبات النازحات من خلال:

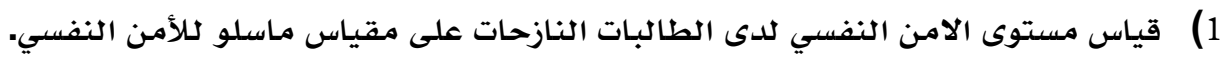
2) تحليل رسوم الطالبات النازحات على استمارة تحليل الرسوم.

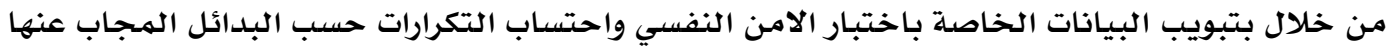

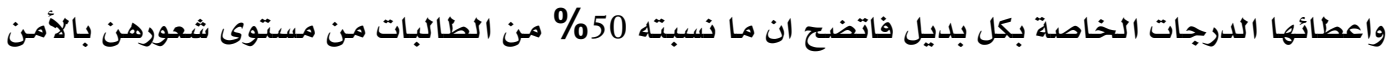

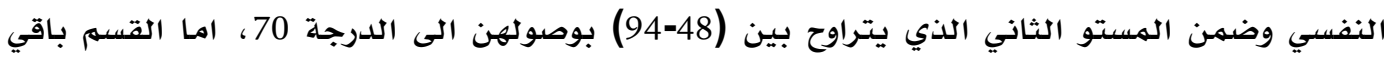

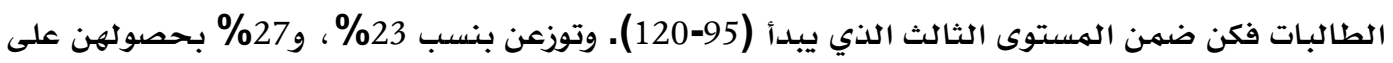

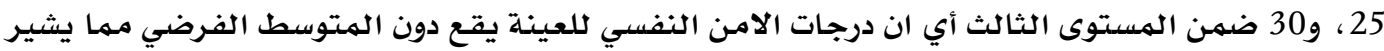

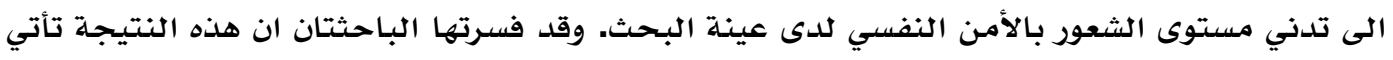

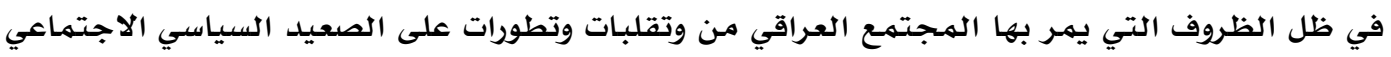

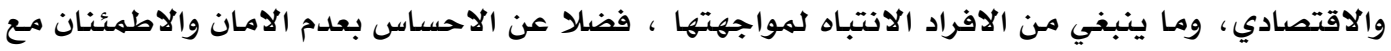

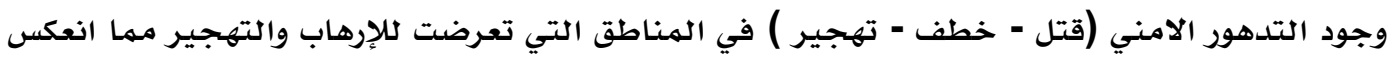

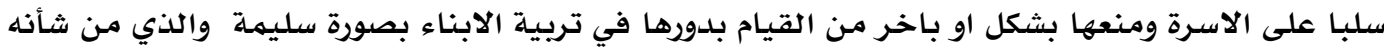

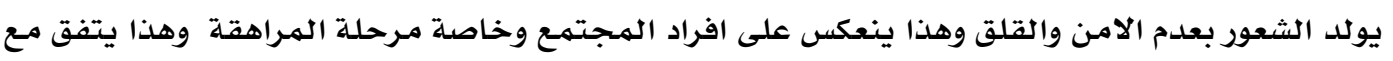

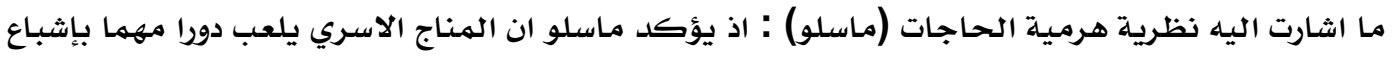

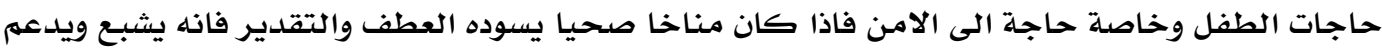
حاجات الطفل بينما يضطرب اشباع هذه الحاجات في المناج الاسري المضطرب المادي المشحون بالخوف والقلق.

اما فيما يخص الهدف الثاني: تعرف مستوى الامن النفسي في رسوم الطالبات النازحات من خلال: تحليل

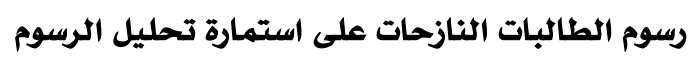

فقد تحقق هذا الهدف من خلال اعداد الباحثتان لأداة تحليل رسوم الطالبات واستخلاص النقات النتائج وتحليلها

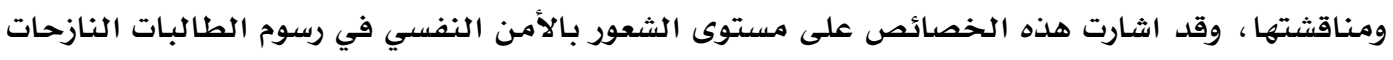

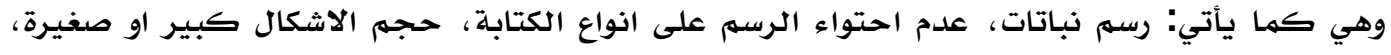

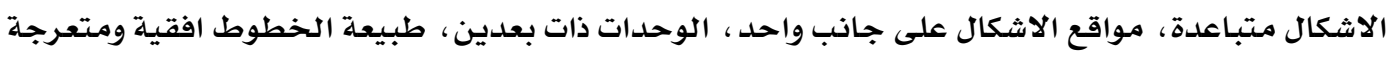

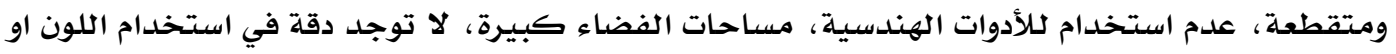
مزخخ للألوان

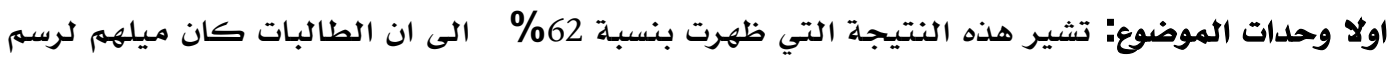

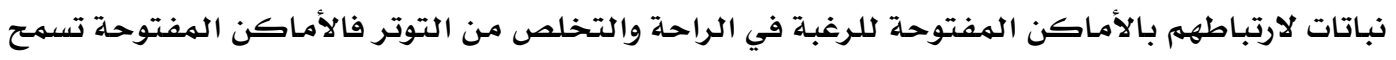
لهم بالانعزال عن الاخرين.

Ali, N. Ali, S. (2019). Representations of psychological security in the artistic expression of displaced students. Journal Port Science Research, 2(2), 203-212. 


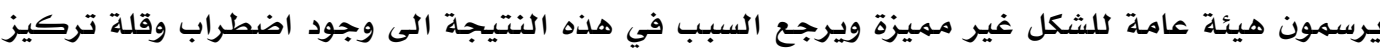
والانتباه لكلأثياء والشعور بالخوف من التركيز والاهتمام بالتفاصيل الصغيرة فالشخص الذي لاني لا يشعر

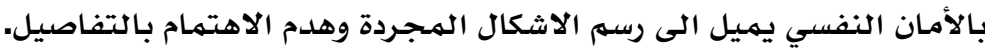
ثالثا الخطوط: فقد شكله نسبة 23\% للخطوط الافقية و62\% للخطوط المتقطعة ويرجع تفسير هذه النتيجة الى ان الطالبـات اللواتي يشعرن بمستوى متدني من الامن النفسي يميلون الى رسهم خطوط

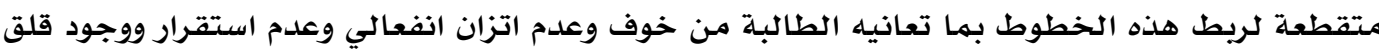
ينتاب الطالبة من الخوف من المجهول والحاجـة الى التعويض لعدم الاستقرار مـ خلال ميله لرسهم خطوط افقية وخوفه من المغامر بالرسهم العامودي اضافة الى التحاشي للظهور امـام الاخرين

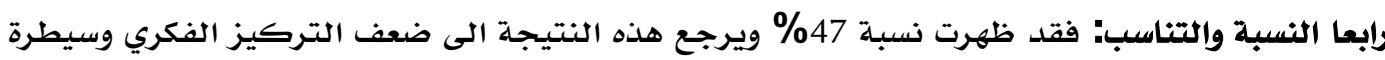
المخيلة الهثيرة للخطر والافكار المخيفة لذلك تحدد نسبة الاشكال الى انطباعها المنظوري الذاتي بغض النظر عن موضوعتيه نتيجة لما تمثلـه هذه الوحدات بالنسبـة لها.

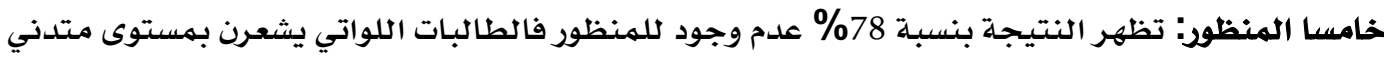

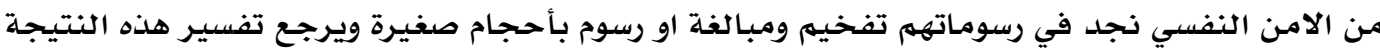
الى الانقباض وعدم الرغبة في التفاعل مـع الاخرين لخوفهم من الغرباء والشعور بالنقص وانخفاض تقدير

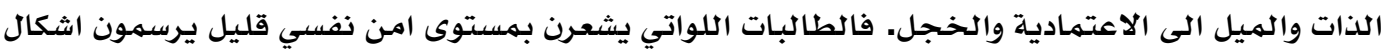
متبـاعدة نتيجة الرغبـة بالانعزال والخوف من الاخرين والابتعاد عنهم والرغبـة في البقاء وحيدا فيرسمون تراكيب الاشكال تعطي رموز دلالية تعطي ايحاء بالمنظور مما يدل على ضعف المستوى الذهني والادراكي لإبعاد المنظور في اللوحة سادسا فضاء اللوحة: ان رسم الاشكال الصغير ة او الكبيرة بفضاء واسع يدل على عدم الشعور بالأمان ويمكن تفسير ذلك على اسـاس ان الثقة بالنفس تدفع الطالبة الى ان ترك فضاء خارجي للدلالة على

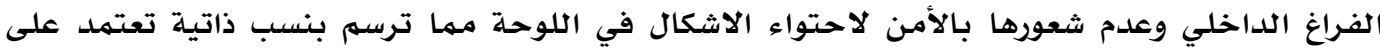
مخيلتها وشعورها واهمال نسب الاشكال في الواقع. سابعا الالوان : ظهرت بنسبة 34\% من ناحية طبيعة الالوان واستخدامها لكلألوان الاساسية وخاصدة اللون الازرق بوصفة من الالوان الباردة فالطالبـة تستخدم الالوان التي تشعرها بالسعادة مبتعدة عن الالوان الحارة

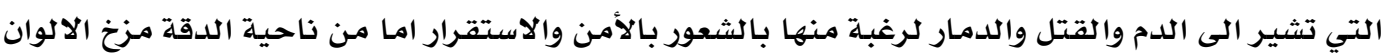

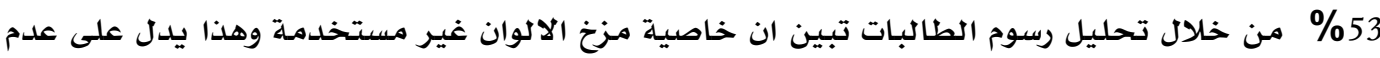

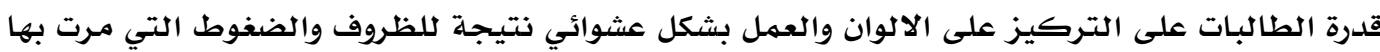
وعدم مزخ اللون التي تعدها مغامـرة لإنتاخ الوان جديدة وفقدان روح المغامـرة ولإنتاخ وخوفها من الفشل

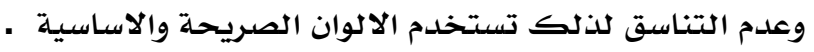

\section{4. الاستنتاجات}

$$
\text { في ضوء ما أسفر عنه البـحث من نتائج وتفسير تلك النتائج استنتج الاتي: }
$$

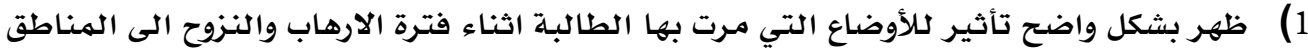
المـجاورة ومن ثم على تعبيرها من خلال الرسم خاصـة انعدام الامن مما يؤثر على مستوى الدافعية وتعزيز الخوف من المجهول. 
2) ان مستويات الشعور بالأمن النفسي كانت متباينة بين الحالة المتوسطة الضعيفة ويعود

الاختلاف في ذلك الى تباين الحالة والظروف التي مرت بها كل طالبـة واختالاف الهناطق.

3) هناك ضعف واضح في مـزج الالوان لدى الطالبـات ذوات الشعور بـالأمن النفسي المنخفض بسبب

الخوف مـن المغامـرة والذي انعكس في تعبيرهم الفني من خلال الرسم

4) تميل الطالب ذات الثعور بالأمـن النفسي الهتدني الى التضخيهم والهبـالغة في الرسم فضلا

اضفاء نوع مـن التعويض للوصول الى حالية الاستقرار.

5. 5 التوصيات

في ضوء نتائج البحث توصي الباحثتان بالآتي:

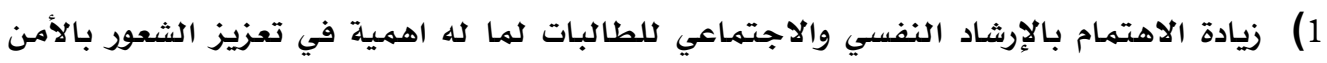

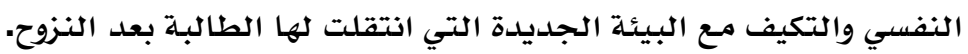

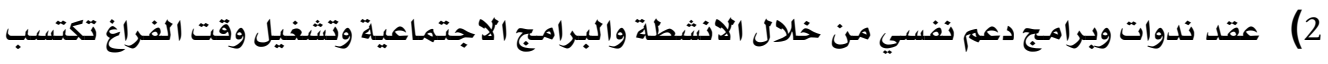

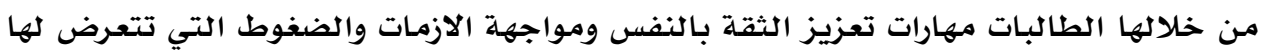

في حياتها.

\section{References}

[1] Al-Nahi, Essam Mohammed Abdel-Raza (2012). الأمن النفسي و علاقته بمستوى الاستثارة الانفعالية لدى لاعبي كرة السلة >. (Master Thesis), University of Mosul, Faculty of Physical Education. http: / / thesis.mandumah.com/Record/156005

[2] Mutlaq, Fatima Abbas. (1994). بناء مقياس مقنن للأمن النفسي لطلبة جامعة بغداد> > (Master Thesis), Baghdad University. http://www.iraqnlaiq.com/opac2 / fullrecr.php?nid=2170\&hl=ara

[3] Hassan, Mostafa Mohamed Abdel Aziz. (2006). سيكولوجية التعبير الفني عند الأطفال> >. Cairo: The Anglo - Egyptian Library. http://maktabat.mu.edu.sa/cgi-bin/koha/opacdetail.pl?biblionumber $=11379 \% 20$ thumbnail-shelfbrowser

الفن الأوروبي الحديث / تأليف آلان باونيس ؛ ترجمة فخري خليل ؛ مراجعة جبرا > .(1994) .باونيس ، آلان [4] > . Beirut, Lebanon: Arab Institute for Studies and Publications. https: / / libserver.bethlehem.edu/webopac/records/1/82202.aspx

[5] Al-Alusi, Jamal Hussein. (1988). الاسس النقية لآراء الماوردي التريوية> Baghdad: Baghdad Press. http: / / www.iraqnla-iq.com/ opac/ fullrecr.php?nid=5607\&hl=ara

[6] The Canaanite, Mamdouh Abdel Moneim. (1988). مدي تحقق التنظيم الهرمي للحاجات عند ماسلو > Journal of Faculty of Education Mansoura.

Ali, N. Ali, S. (2019). Representations of psychological security in the artistic expression of displaced students. Journal Port Science Research, 2(2), 203-212. 
[7] Zahran, Hamid Abdel Salam. (1980). الامن النفسي دعامة اساسية للأمن القومي> > Journal of Educational Studies, 4(19).

[8] Adas, Abdul Rahman. (1996). الاسلام والامن النفسي للإفراد>> Journal of Security and Life Issue 169. https:// repository.nauss.edu.sa/handle/123456789/60677?show=full

[9] Al-Tantaji, Taghreed Khalil Ghani. (1997). بناء برنامج ارشادي جمعي كلامن والنفس واثره في التفكير الابتكاري لدى طلبة الجامعة > (Doctoral Thesis), Baghdad: University of Baghdad, Faculty of Education. http:/ / www.iraqnla-iq.com/opac2/ fullrecr.php?nid=9657\&hl=ara

[10] Londerville, S., \& Main, M. (1981). Security of attachment, compliance, and maternal training methods in the second year of life. Developmental Psychology, 17(3), 289-299. https:// doi.org/10.1037/0012-1649.17.3.289

[11] Cooper, J. O. (1982). Applied Behavior Analysis in Education. Theory into Practice, 21(2), 114-118. https: / / doi.org/10.1080/00405848209542992 